\title{
A INCLUSÃO DE ALUNOS PÚBLICO-ALVO DA EDUCAÇÃO ESPECIAL NA EDUCAÇÃO SUPERIOR: UM ESTUDO DE CASO SOBRE O TRABALHO DOCENTE COM UMA ALUNA SURDA NO CURSO DE PEDAGOGIA
}

\author{
LA INCLUSIÓN DE ALUMNOS PÚBLICO-PUNTO DE LA EDUCACIÓN \\ ESPECIAL EN LA EDUCACIÓN SUPERIOR: UN ESTUDIO DE CASO SOBRE \\ EL TRABAJO DOCENTE CON UNA ALUNA SURDA EN EL CURSO DE \\ PEDAGOGÍA
}

\author{
THE INCLUSION OF TARGET STUDENTS OF SPECIAL EDUCATION IN \\ HIGHER EDUCATION: A CASE STUDY ON THE TEACHING WORK WITH A \\ DEAF STUDENT IN THE COURSE OF PEDAGOGY
}

\author{
Roberta Aline SBRANA ${ }^{1}$ \\ Relma Urel Carbone CARNEIRO ${ }^{2}$
}

RESUMO: Este artigo busca verificar como tem ocorrido o processo de inclusão de alunos Público-Alvo da Educação Especial na Educação Superior. Inicialmente apresenta-se um breve histórico da Educação Especial e da Educação Superior no Brasil, evidenciando, ao longo dos anos, de que modo as Instituições de Educação Superior e a legislação têm garantido aos alunos o acesso e a permanência nesse nível de ensino e, consequentemente, o processo de inclusão. A partir desse contexto, o objetivo deste estudo foi investigar o trabalho desenvolvido por uma professora com uma aluna surda, no curso de Pedagogia de uma Instituição de Educação Superior, a fim de verificar como ocorre o processo de inclusão desta aluna. Com uma abordagem qualitativa, desenvolvemos um estudo de caso analisando os dados a partir da análise de conteúdo. Para a coleta de dados foi realizada uma entrevista semiestruturada com a mencionada professora. As discussões e resultados estão organizados nas seguintes categorias: a) Identidade profissional; b) Trabalho docente e inclusão; c) A IES e o processo de inclusão; e d) A relação docente - instituição - família; embora essas categorias apontem a garantia do acesso e permanência dessa aluna na referida Instituição, conclui-se, entretanto, a não efetividade do processo de inclusão devido à inexistência de uma prática pedagógica inclusiva.

PALAVRAS-CHAVE: Inclusão. Educação superior. Trabalho docente.

RESUMEN: Este artículo busca verificar cómo ha ocurrido el proceso de inclusión de alumnos Público-Objetivo de la Educación Especial en la Educación Superior. En principio se presenta un breve histórico de la Educación Especial y de la Educación

\footnotetext{
${ }^{1}$ Universidade Estadual Paulista (UNESP), Araraquara - SP - Brasil. Doutoranda do Programa de PósGraduação em Educação Escolar. Pedagoga e Mestre em Educação. ORCID: <https://orcid.org/00000002-6514-6946>. E-mail: robertaasbrana@gmail.com

${ }^{2}$ Universidade Estadual Paulista (UNESP), Araraquara - SP - Brasil. Docente do Departamento de Psicologia da Educação e do Programa de Pós-graduação. ORCID: <https://orcid.org/0000-0002-89613617>. E-mail: relmaurel@fclar.unesp.br
} 
Superior en Brasil, evidenciando a lo largo de los años como las Instituciones de Educación Superior y la legislación han garantizado a estos alumnos el acceso y la permanencia en este nivel de enseñanza y, consecuentemente el proceso de inclusión. A partir de este contexto, el objetivo de este estudio fue investigar el trabajo desarrollado por una profesora con una alumna sorda, en el curso de Pedagogía de una Institución de Educación Superior, a fin de verificar cómo viene ocurriendo el proceso de inclusión de esta alumna. Con un enfoque cualitativo, desarrollamos un estudio de caso analizando los datos a partir del análisis de contenido. Para la recolección de datos se realizó una entrevista semiestructurada con la mencionada profesora. Las discusiones y resultados se organizan en las siguientes categorías: a) identidad profesional; $b$ ) Trabajo docente e inclusión; c) la IES y el proceso de inclusión; d) la relación docente - institución - familia; las cuales apuntan a la garantía del acceso y permanencia de esa alumna en dicha institución. Sin embargo, se concluye, la no efectividad del proceso de inclusión debido a la inexistencia de una práctica pedagógica inclusiva.

PALABRAS CLAVE: Inclusión. Educación superior. Trabajo docente.

ABSTRACT: This article pursuit verify as has been the inclusion process of Students target audience of Special Education in Higher Education. At first presents a brief history of Special Education and Higher Education in Brazil, showing over the years as the higher education institutions and legislation have guaranteed these students access and permanence at this level of education and consequently the inclusion process. From this context, the aim of this study was to investigate the work of a teacher with a deaf student the course of Pedagogy of a higher education institution in order to verify comes happening the inclusion process of this student. With a qualitative approach, we developed a case study analyzing the data from the content analysis. For data collection was carried out half structured interviews with the teacher. The discussions and results are organized in the following categories: a) Professional identity; b) Teaching work and inclusion; c) The IES and the inclusion process; and d) The teacher - institution family relationship; they point to guarantee access and permanence of that student in that institution. However, concludes, not effectiveness of the inclusion process in the absence of an inclusive pedagogical practice.

KEYWORDS: Inclusion. Higher education. Teaching work.

\section{Introdução}

No Brasil, o primeiro "movimento em prol da educação especial" foi representado pela criação, no Período Imperial, do Instituto dos Meninos Cegos (atual IBC), em 1854, e do Instituto De Surdos-Mudos (atual INES), em 1857. A “preocupação com a educação dos diferentes"3 teve início no Império, mas se intensificou no final do século XIX, momento em que os "ideais liberais começaram a ser discutidos e consolidados". Nesse período, de acordo com Vieira (2013, p. 04), a educação especial é caracterizada

\footnotetext{
${ }^{3}$ Termo utilizado pela autora.
} 
A inclusão de alunos público-alvo da educação especial na educação superior: um estudo de caso sobre o trabalho docente com uma aluna surda no curso de pedagogia

pela "institucionalização das pessoas com deficiência"4; o intuito era "proteger da sociedade" tais pessoas colocando-as em instituições especializadas, que apresentavam um “[...] caráter mais assistencial com práticas clínicas do que uma perspectiva educacional" (SILVA, 2009, p. 03).

Com a Proclamação da República em 1889, as mudanças econômicas, sociais e políticas ocorridas no país influenciaram a educação. Os primeiros anos do século XX apresentaram uma expansão da educação pública, influenciada pelo Movimento da Escola Nova que se desenvolveu no Brasil durante as décadas de 1920 e 1960. Uma das preocupações desse Movimento era "reduzir as desigualdades sociais", por isso “incorporava em suas metodologias pedagógicas" as "concepções de profissionais, como Decroly e Montessori" que trabalhavam com a educação especial. As reformas educacionais implementadas nessas décadas, mediante os princípios escolanovistas, influenciaram os "rumos da educação especial brasileira"; mesmo defendendo a "diminuição da desigualdade social", esse Movimento contribuiu para a "exclusão" dos alunos Público-Alvo da Educação Especial ${ }^{5}$ (doravante alunos PAEE) das escolas regulares ao propor "um adequado e especializado ensino" a esses alunos, que "não atendiam às exigências dessas escolas" (JANNUZZI, 1992 apud SILVA, 2009, p. 04)6 .

Essa expansão da educação pública no Brasil e a influência dos princípios escolanovistas também se estenderam à Educação Superior. Nas décadas de 1910 e 1920 foram criadas as primeiras Universidades públicas nos Estados do Paraná e Rio de janeiro, respectivamente. Com a publicação do "Manifesto dos Pioneiros da Educação Nova" (1932), foram lançadas as "bases da concepção de Universidade com tríplice função: pesquisa, docência e extensão", que enfatizava o "lugar central da pesquisa". Tal documento ainda "criticava as instituições de ensino superior existentes até então, cujos objetivos não iam além da formação profissional”. Nessa época, o acesso a esse nível de ensino era restrito a uma parcela da população, os jovens da classe média e sua finalidade era manter o "status de tal classe", com a formação de uma elite intelectual (FERRARI; SEKKEL, 2007, p. 639-640).

Nas décadas de 1930 e 1940, com a implantação daquelas reformas educacionais em diferentes estados brasileiros, houve uma contínua expansão da educação pública, e

\footnotetext{
${ }^{4}$ Termo utilizado historicamente e mantido pela autora.

${ }^{5}$ Como estabelecido pela Política Nacional de Educação Especial na Perspectiva da Educação Inclusiva (2008), os alunos Público-Alvo da Educação Especial são aqueles com deficiência, transtornos globais de desenvolvimento e altas habilidades/superdotação.

${ }^{6} J A N N U Z Z I$, G. A luta pela educação do deficiente mental no Brasil. São Paulo: Editores Associados, 1992.
} 
consequentemente do Ensino Superior, que tem como marco importante a criação da Universidade de São Paulo (1934). Esse crescimento, no entanto, não se estendeu à Educação Especial, já que, nesse período, tal Educação "não era considerada um problema a ser resolvido" e a preocupação daquelas reformas era a educação regular. Essa realidade sofreu algumas alterações nos anos de 1950, quando se intensificaram no cenário internacional as "discussões sobre a qualidade dos serviços educacionais especiais". A partir de então, houve uma "rápida expansão das classes e escolas especiais nas escolas públicas" e, principalmente "de escolas especiais comunitárias privadas e sem fins lucrativos", pois, apenas em 1957, “o governo federal assumiu em âmbito nacional o atendimento educacional" dos alunos PAEE, com algumas campanhas, sendo que a primeira delas, a "Campanha para a Educação do Surdo Brasileiro", foi realizada neste mesmo ano (MIRANDA, 2008, p. 34).

Nos anos de 1970 e 1980, esse contexto se alterou com o surgimento no Brasil de novos discursos sobre a Educação Especial pautados no "princípio de normalização", que previa que os alunos PAEE “deveriam ser educados num ambiente o mais normal possível, oferecendo a eles recursos materiais o mais próximo possível dos demais alunos", evitando assim, sua "segregação". Nesse período, a "integração se constituiu numa modalidade de atendimento da Educação Especial" e aos poucos, alguns alunos PAEE, segundo suas "capacidades", passaram a ser integrados à educação regular. Com essa "integração, esperava-se que o aluno, a partir da educação especial, se tornasse competente o suficiente para acompanhar o ensino regular". A escola, nessa modalidade, "assume uma postura individualista ao se concentrar nas capacidades pessoais" do aluno PAEE para se "adaptar ao cotidiano escolar", não considerando suas "diferenças individuais, sociais e culturais"; nesta modalidade, "transfere-se" para esses alunos a "responsabilidade de adaptação ao modelo escolar" existente, "sem questionar sua estrutura" (MIRANDA, 2008, p. 37-38).

Essas mudanças ocorridas na Educação Especial não se estenderam à Educação Superior, que na década de 1980 ainda apresentava restrições de acesso à população. A quantidade de alunos PAEE que ingressava na Educação Superior era diminuta, devido, ainda ao seu "não acesso à educação básica". No ano de 1981, com a instituição do “Ano Internacional da Pessoa com Deficiência”, e no período de 1983 a 1992, da

7 Os alunos com deficiências leves (dificuldade de aprendizagem, distúrbio de comportamento, deficiência mental leve) eram encaminhados para as classes especiais, onde recebiam apoio pedagógico especializado. Os alunos que apresentavam deficiências graves (deficiência moderada e severa, deficiência múltipla) eram encaminhados para as escolas especiais. 
A inclusão de alunos público-alvo da educação especial na educação superior: um estudo de caso sobre o trabalho docente com uma aluna surda no curso de pedagogia

"Década das Nações Unidas para a Pessoa com Deficiência", tiveram início os debates sobre a exclusão social e educacional vivenciada por essas pessoas. A partir desses debates começou-se a apresentar alguma possibilidade de ingresso dos alunos PAEE na Educação Superior. Entretanto, com a ausência das "adaptações necessárias nos processos seletivos", esse acesso continuou restrito e quando se efetivava, a permanência do aluno era comprometida devido à existência de "barreiras arquitetônicas, atitudinais e de aprendizagem" (BRITO; QUIRINO; PORTO, 2013, p. 17).

Apesar da Constituição Federal, em 1988, já ter definido, no artigo 205, a educação "como um direito de todos e dever do Estado e da família", no artigo 206, inciso I, que o ensino deveria ter como um dos seus princípios a "igualdade de condições para o acesso e permanência na escola", e no artigo 208, inciso III, a realização do "atendimento educacional especializado aos portadores de deficiência, preferencialmente na rede regular de ensino" (BRASIL, 1988), a realidade na Educação Superior no Brasil somente sofreu algumas mudanças na década de 1990 com a criação das Instituições privadas. Com o elevado número de vagas oferecido nestas Instituições, uma "população maior e mais variada", anteriormente segregada, constituída por alunos das camadas mais pobres, negros e os alunos PAEE, passou a ter maior possibilidade de acesso a este nível de ensino (FERRARI; SEKKEL, 2007, p. 640). No entanto, a existência daquelas "barreiras arquitetônicas, atitudinais e de aprendizagem" ainda comprometia a permanência dos alunos PAEE nestas Instituições (BRITO; QUIRINO; PORTO, 2013, p. 17).

Ainda nos anos de 1990, a Educação Superior no Brasil sofreu influências com o surgimento dos movimentos em defesa da educação inclusiva e, a partir disso, inicia-se os debates sobre a inclusão na Educação Superior, que apontavam maior possibilidade, não apenas de acesso, mas de permanência de toda aquela população historicamente segregada deste nível de ensino, dentre eles os alunos PAEE (MENDES; BASTOS, 2016, p. 191). Esses movimentos eram pautados no "paradigma da inclusão", que contrário ao "processo de integração", previa, no âmbito educacional, a inserção de todos os alunos na escola e no processo educativo, a partir do reconhecimento da “existência de inúmeras diferenças (pessoais, linguísticas, culturais, sociais etc.)”. Tal reconhecimento aponta a "necessidade de mudança do sistema educacional", que, "na 
realidade, não se encontra preparado para atender a essa clientela" e sua diversidade (BUENO, 1999 apud MIRANDA, 2008, p. 39) ${ }^{8}$.

Com o surgimento desse "novo paradigma", houve, durante os anos de 1990, a elaboração de diversos documentos que apontavam a criação de uma educação inclusiva, tais como a "Declaração Mundial de Educação para Todos" (1990) e a "Declaração de Salamanca" (1994), que "[...] previa providências para crianças, jovens e adultos com necessidades educacionais especiais dentro do sistema regular de ensino". Diante de sua concordância com esses documentos, o Brasil assumiu o "compromisso pela construção de um sistema educacional inclusivo", ocasionando "transformações" no sistema até então existente e, consequentemente na "legislação para a educação". A promulgação da "Lei de Diretrizes e Bases da Educação Nacional, no 9394/96", é um desses exemplos, pois, além de perpassar todos os níveis de ensino, ela dedicou o Capítulo IV à Educação Superior e o Capítulo V à Educação Especial (FERRARI; SEKKEL, 2007, p. 641).

Quanto à criação de uma educação inclusiva na Educação Superior, houve na década de 1990 a "Conferência Mundial sobre a Educação Superior" (1998), que apresentou como uma de suas ideias principais que "o acesso aos estudos superiores será igual para todos" (CASTANHO; FREITAS, 2006, p. 97). No que tange, especificamente, à inclusão dos alunos PAEE neste nível de ensino, em 1996, o Aviso Circular n. 277 MEC/GM, dirigido aos Reitores das Instituições de Ensino Superior ${ }^{9}$ (doravante IES) solicitava a "execução adequada de uma política educacional" diante da "necessidade de ampliação do acesso" desses alunos a Educação Superior, "propondo atenção das Universidades em três aspectos: na elaboração do edital do concurso de vestibular, no momento da realização das provas e no processo de correção das provas" (MEC, 1996).

Anache, Rovetto e Oliveira (2014, p. 301) ainda destacam que, o Ministério da Educação (doravante MEC) considerando o disposto na Lei $\mathrm{n}^{\circ}$ 9.131/95, na Lei $\mathrm{n}^{\circ}$ 9.394/96 e no Decreto $n^{\circ}$ 2.306/97, determinou que fossem "incluídos os instrumentos destinados a avaliar as condições de oferta de cursos superiores", visando sua "autorização e reconhecimento, para fins de credenciamento" das IES, bem como para

${ }^{8}$ BUENO, J. G. S. Crianças com necessidades educativas especiais, política educacional e a formação de professores: generalistas ou especialistas? Revista Brasileira de Educação Especial, v. 3, n. 5, p. 07-26, 1999.

${ }^{9}$ A expressão "Instituições de Ensino Superior", representada pela sigla "IES”, se refere às instituições públicas e privadas deste nível de ensino. 
A inclusão de alunos público-alvo da educação especial na educação superior: um estudo de caso sobre o trabalho docente com uma

sua "renovação", exigindo, os requisitos necessários para assegurar aos alunos PAEE a "mobilidade e utilização de equipamentos e instalações" presentes nessas Instituições, para garantir sua acessibilidade a Educação Superior.

Segundo Miranda (2008, p. 40), mesmo diante da legislação produzida nos anos de 1990 e 2000, é preciso considerar que a "efetivação" de uma educação inclusiva não ocorre somente por "meio de leis, decretos ou portarias que obriguem as escolas regulares a aceitarem" todos os alunos, mas somente se a "escola estiver preparada para trabalhar com os alunos que chegam até ela, independentemente de suas diferenças ou características individuais", apresentando condições para um acesso e permanência de qualidade, a partir da organização do trabalho pedagógico e das ações docentes. Para tanto, a escola precisa de "uma transformação radical, pois caberá a ela adaptar-se às condições dos alunos, ao contrário do que acontece hoje, quando os alunos é quem tem que se adaptar à escola" (MIRANDA, 2008, p. 40).

Além disso, cabe aos Sistemas de Ensino organizar condições que garantam o acesso a todos os "espaços, recursos pedagógicos e de comunicação" existentes nas Instituições Educativas possibilitando que a aprendizagem seja garantida a todos os alunos igualmente, efetivando sua permanência nestas Instituições (CAMPOS, 2011, p. 02). Na Educação Superior, essa necessária organização tem sido largamente discutida na atualidade, segundo Mendes e Bastos (2016, p. 191). A busca de "ampliação do acesso" às IES, pela "garantia das condições de acessibilidades físicas e metodológicas" e de um "ensino de qualidade" para todos, que "assegure sua permanência" nestas Instituições, tem sido um dos seus "grandes desafios".

No que tange especificamente ao acesso de alunos PAEE na Educação Superior, alguns trabalhos (ROCHA; MIRANDA, 2009; BRITO; QUIRINO; PORTO, 2013; ANACHE; ROVETTO; OLIVEIRA; 2014; MENDES; BASTOS, 2016) revelam que houve um crescimento das matrículas desses alunos nas IES durante os anos 2000, entretanto, esse crescimento ainda é pequeno se comparado à quantidade das demais matrículas neste nível de ensino. É importante destacar também que a maioria das matrículas dos alunos PAEE está nas Instituições privadas e seu acesso às Instituições públicas é menor. Esse aumento do acesso de alunos PAEE à Educação Superior se deve ao fato de que algumas Instituições vêm desenvolvendo "ações importantes" durante o processo de seleção, tais como as "provas ampliadas para pessoas com baixa visão" e as "bancas especializadas", que possuem, por exemplo, "professor intérprete 
para surdos", o que contribui para viabilizar o acesso destes alunos a este nível de ensino (MENDES; BASTOS, 2016, p. 192-193).

Alguns programas governamentais também se constituem como facilitadores do acesso de alunos PAEE na Educação Superior. Um exemplo é o Programa Incluir (Programa de Acessibilidade na Educação Superior), criado em 2005, desenvolvido pela Secretaria da Educação Superior (SESU) e pela extinta Secretaria de Educação Especial (SEESP) criada pelo MEC, que tem "como objetivo promover o cumprimento dos requisitos legais de acessibilidade" garantindo aos alunos PAEE "o acesso às Instituições Federais de Ensino Superior, a partir da criação dos núcleos de acessibilidade" (ANACHE; ROVETTO; OLIVEIRA, 2014, p. 302).

Contudo, segundo Ferrari e Sekkel (2007, p. 642), as "práticas educacionais voltadas à inclusão" na Educação Superior ainda são "escassas" e, em muitos casos, elas se configuravam apenas por meio de "ações afirmativas" como as cotas sociais e raciais voltadas principalmente para a "inclusão das camadas mais pobres da população ou para estudantes negros" e, nesse caso, os alunos PAEE "somem de cena". Como afirmam Anache, Rovetto e Oliveira (2014, p. 301), é difícil encontrar alunos PAEE que concluem seus estudos na Educação Superior e que possuem "condições socioeconômicas e culturais mais favoráveis para removerem as barreiras existentes".

Para tanto, como afirmam Mendes e Bastos (2016, p. 192-193), o processo de inclusão de alunos PAEE na Educação Superior requer que as IES e os governos ofereçam, não apenas "ações afirmativas" e programas que garantam seu acesso a esse nível de ensino, mas também os "recursos necessários" para constituição de "práticas educacionais inclusivas", que contribuam para a construção de uma educação inclusiva, garantindo seu aprendizado e permanência nestas Instituições, rompendo, assim, as "barreiras programáticas e atitudinais" existentes. A formação continuada de professores para o exercício da docência, e o oferecimento do Atendimento Educacional Especializado (doravante AEE) aos alunos PAEE, são dois exemplos desses "recursos".

Segundo o Decreto $\mathrm{n}^{\mathrm{o}} 7.611 / 11^{10}$, o AEE se constitui como "serviços de apoio especializado" que visam "eliminar as barreiras que possam obstruir o processo de escolarização" dos alunos PAEE. No artigo $5^{\circ}$, parágrafo $3^{\circ}$, deste Decreto, o AEE deve ser ofertado nas salas de recursos multifuncionais (SRMs), caracterizadas como “ambientes dotados de equipamentos, mobiliários e materiais didáticos e pedagógicos".

${ }^{10}$ Este Decreto revogou a antigo Decreto $\mathrm{n}^{\circ}$ 6.571/08 que dispunha sobre o AEE. 
A inclusão de alunos público-alvo da educação especial na educação superior: um estudo de caso sobre o trabalho docente com uma aluna surda no curso de pedagogia

Sobre o AEE na Educação Superior, esse Decreto, em seu artigo $5^{\circ}$, menciona a "estruturação de núcleos de acessibilidade nas instituições federais", com o apoio técnico e financeiro prestado pela União "aos sistemas públicos de ensino dos Estados, Municípios e Distrito Federal, e a instituições comunitárias, confessionais ou filantrópicas sem fins lucrativos" (BRASIL, 2011).

Para Anache, Rovetto e Oliveira (2014, p. 303), o AEE é recente na Educação Superior, devido ainda ao pequeno contingente de alunos PAEE que chegam a esse nível de ensino. De acordo com Alcoba (2008 apud ANACHE; ROVETTO; OLIVEIRA, 2014, p. 304) ${ }^{11}$, o AEE “deve integrar a infraestrutura básica da Universidade", como sua "biblioteca ou os laboratórios de informática". Todos os espaços "deveriam disponibilizar recursos adaptados" que possibilitassem a todos os alunos a convivência social e o aprendizado.

Segundo Pacheco e Costas (2006, p. 157), a inclusão de alunos PAEE na Educação Superior ainda "requer medidas que facilitem e auxiliem a concretização desse processo", tais como: "a formação continuada de professores, a produção e adequação de recursos pedagógicos, a assessoria psicopedagógica, a adaptação do currículo e a reflexão de todos os envolvidos no processo educativo", além da "criação de comissões ou núcleos na própria instituição responsáveis pelo desenvolvimento de ações que propiciem a inclusão".

A ausência de formação continuada para os professores das IES dificulta a criação de uma "prática educacional inclusiva", impondo barreiras à permanência dos alunos PAEE na Educação Superior, além de despertar, por vezes, nestes profissionais "sentimentos de ansiedade e rejeição" ao ter que, em algum momento de sua trajetória, desenvolver um trabalho com estes alunos em sala de aula. Por essa razão, esses professores "precisam compreender que todos os indivíduos apresentam características distintas" e que, portanto, eles "precisam estar capacitados para atender todos os alunos" (PACHECO; COSTAS, 2006, p. 165).

Por ser a inclusão na Educação Superior uma "discussão recente", ela exige do professor das IES “ações pautadas não só em políticas públicas como também numa prática reflexiva". Para Perrenoud (2002, p. 47), a "prática reflexiva deve constituir as bases de uma análise metódica, regular, instrumentalizada, serena e causadora de

${ }^{11}$ ALCOBA, S. A. C. Estranhos no ninho: a inclusão de alunos com deficiência na Unicamp. 2008. 231 f. Tese (Doutorado em Educação Especial) - Faculdade de Educação, Universidade Estadual de Campinas, Campinas, SP, 2008. 
efeitos", que não se limita "ao bom senso e a experiência pessoal". Para a realização de seu trabalho, o professor necessita de "saberes que não pode reinventar sozinho", mas somente a partir da reflexão. Nesse processo, também é "necessário reconhecer o professor e valorizá-lo enquanto ser inacabado" e "ressignificar os processos educativos, admitindo uma formação reflexiva”. Para Castanho e Freitas (2006, p. 96), "apontar caminhos para a mudança" na "prática pedagógica dos professores que atuam no Ensino Superior" e no "projeto de organização das IES é premente" para favorecer as "políticas de inclusão neste universo".

A partir dessas questões apresentadas, a bibliografia consultada aponta que o processo de inclusão de alunos PAEE na Educação Superior encontra-se em estágio inicial. Apesar da ampliação do acesso, os recursos para garantia da permanência, como a existência de uma "prática educacional inclusiva", que configure uma educação inclusiva, ainda são inexistentes em muitos casos, contribuindo para a não efetividade desse processo. Partindo do contexto alvitrado, realizamos uma pesquisa com o objetivo investigar o trabalho desenvolvido por uma professora com uma aluna surda em uma sala de aula comum, do curso de Pedagogia de uma IES, a fim de verificar como vem ocorrendo o processo de inclusão desta aluna.

\section{Método}

Com uma abordagem qualitativa, esta pesquisa se constitui como um estudo de caso, que "consiste na observação detalhada de um contexto, ou indivíduo, de uma única fonte de documentos ou de um acontecimento especifico" (ANDRÉ, 2005 apud ALMEIDA; SILVINO, 2010, p. 04) ${ }^{12}$. Um caso é "uma unidade específica, um sistema delimitado cujas partes são integradas" (STAKE 2000 apud ALVES-MAZZOTTI, 2006, p. 640-641) $)^{13}$.

Para coleta de dados foi utilizada uma entrevista semiestruturada, elaborada por nós pesquisadoras, composta por treze questões abertas. Diante do objetivo desta investigação, a referida entrevista foi realizada com uma professora do curso de Pedagogia, de uma IES localizada no estado de Goiás. Essa profissional trabalhou 35 anos na Educação Básica, e atua no Ensino Superior a 20 anos. É graduada em Pedagogia, Mestre em Educação e está cursando Doutorado, também em Educação.

${ }^{12}$ ANDRÉ, M. Etnografia da prática escolar. Campinas: Papirus, 2005.

${ }^{13}$ STAKE. R. E. Case studies. In: DENZIN, N. K.; LINCOLN, Y. S. Handbook of qualitative research. London: Sage, 2000. 
A inclusão de alunos público-alvo da educação especial na educação superior: um estudo de caso sobre o trabalho docente com uma aluna surda no curso de pedagogia

Atualmente, trabalha, em uma das turmas do mencionado curso com uma aluna surda, de 22 anos, que está cursando o sétimo semestre.

Para a análise e discussão dos resultados obtidos com esta entrevista, utilizou-se o método de análise de conteúdo, concebido como uma “[...] ferramenta para a compreensão da construção de significado que os atores sociais exteriorizam no discurso" (BARDIN, 1994 apud SILVA; GOBBI; SIMÃO, 2004, p. 73-74) $)^{14}$. Tais resultados e discussões são apresentados nas seguintes categorias: a) Identidade profissional; b) Trabalho docente e inclusão; c) A IES e o processo de inclusão; e d) A relação docente - instituição - família.

\section{Análise dos resultados e discussão}

Algumas questões que constituem a entrevista serão discutidas nas categorias expostas a seguir. Nesta seção, a docente entrevistada será identificada pela letra "P", para a garantia de seu anonimato.

\section{a) Identidade profissional.}

Esta categoria abarca a questão 1 da entrevista, que questionava a docente - o que é para você ser professor(a)?

Sou professora por opção e vocação. Ser professora é para mim a construção de uma carreira profissional na qual temos desafios e alegrias constantes. Trabalhamos sempre com algo novo. Ser professor é contribuir para o crescimento do ser humano e para isso devemos estar atentos às mudanças e às necessidades e demandas que surgem na sociedade (Professora "P", 2016).

Para Campos (2008 apud BEJA; REZENDE, 2014, p. 159) ${ }^{15}$, essa "representação social da docência" ligada ao "dom e à vocação" trazida, muitas vezes, pelos próprios profissionais e pela sociedade, está diretamente relacionada ao "processo de construção da identidade docente". Entretanto, tal identidade "não pode ser compreendida como algo inexorável ou que possa ser adquirido, mas sim como um espaço de conflitos e embates, como um processo de construção situado sóciohistoricamente", que envolve a "reelaboração contínua dos significados sociais da profissão". Esse processo ainda envolve a "adesão a determinados princípios e valores,

${ }^{14}$ BARDIN, I. Análise de conteúdo. Lisboa: Edições Setenta, 1994.

${ }^{15}$ CAMPOS, J. R. Era um sonho de criança: a representação social da docência para os professores do município de Queimadas - PB. Dissertação (Mestrado), Natal, UFRN, 2008. 
pela ação e pela autoconsciência", pois é no "processo de reflexão sobre a sua prática que o professor vai construindo a sua identidade" (NÓVOA, 2007 apud BEJA; REZENDE, 2014, p. 159) ${ }^{16}$.

Como afirma a professora "P", vivemos em uma sociedade em constante mudança, marcada pela diversidade humana, e o professor, que atua na formação do ser humano, enfrenta a cada dia novos desafios. Um "desafio" constante, segundo Miranda (2008, p. 42), é aquele "colocado pela proposta da escola inclusiva", que assinala a necessidade de desenvolver uma "prática educacional inclusiva" na sala de aula comum que atenda as necessidades educacionais de todos os alunos, dentre eles, os alunos PAEE, permitindo que todos tenham acesso ao conhecimento, garantindo seu aprendizado, desenvolvimento e crescimento.

\section{b) Trabalho docente e inclusão (questões discutidas: 2, 3, 4, 6, 8 e 11).}

Quando indagada sobre sua reação ao saber que teria uma aluna com deficiência em sua turma, a Professora "P" expôs que sua "reação foi de tentar atender a aluna em suas dificuldades e oferecer condições para o sucesso dela na disciplina e durante todo o curso". Mesmo não recebendo nenhuma informação sobre essa aluna, a Professora "P" relata: "Busquei resolver e atender as necessidades da aluna por conta própria e com os conhecimentos adquiridos no curso de graduação (Pedagogia) na minha formação inicial e no curso de Pós-Graduação Lato Sensu em Psicopedagogia”.

As respostas da Professora "P" demonstram uma postura contrária ao que afirma Miranda (2008, p. 42), de que "parte dos professores" devido à "ausência de formação" e da "não-problematização do assunto" apresentam "grande resistência" perante o "desafio" que o processo de inclusão educacional apresenta; mesmo sem receber informações sobre a aluna, sua deficiência e possíveis necessidades, a Professora "P" demonstra em sua fala disposição e iniciativa para atender as necessidades dessa aluna e garantir sua permanência e conclusão satisfatória no curso.

Entretanto, como afirma Prieto (2006, p. 57), para tal garantia é necessário que os sistemas de ensino ofereçam "formação continuada ao professor" para que este seja "apto a elaborar e implantar novas propostas e práticas de ensino para responder às características de todo os seus alunos". Ainda segundo Perrenoud (2002, p.47), os professores precisam assumir "uma prática reflexiva", contudo, essa prática "não pode limitar-se ao bom senso e a experiência pessoal"; para a realização de seu trabalho, o

${ }^{16}$ NÓVOA, A. Vida de professores. 2a ${ }^{\text {a }}$ Ed. Porto: Porto Editora, 2007. 
A inclusão de alunos público-alvo da educação especial na educação superior: um estudo de caso sobre o trabalho docente com uma aluna surda no curso de pedagogia

professor necessita de reinventar saberes a partir da reflexão, "que deverá estar assentada de forma em que haja uma cultura no âmbito das ciências humanas". Para Castanho e Freitas (2006, p. 98), no "Ensino Superior a prática docente" com alunos PAEE “necessita de ações compartilhadas" entre os professores, que sejam "capazes de lhes orientar" na "formação de sujeitos, valorizando a diversidade".

A fala da Professora "P”, quando questionada sobre a presença de alunos PAEE na classe comum, revela exatamente essa consciência da necessidade de uma "formação continuada aos professores" para que eles possam, de fato, desenvolver um trabalho que atenda às necessidades educacionais desses alunos; eis o que ela diz:

Considero a classe comum o lugar para esse aluno, mas acredito que seja necessário mais e melhor formação dos docentes e de apoio técnico e pedagógico especializado, para oferecer condições de aprendizagem a essas pessoas. Não podemos deixa-los incluídos no sistema e excluídos do conhecimento (Professora "P", 2016).

Segundo Prieto (2006, p. 58-59), os “conhecimentos" sobre os alunos PAEE “não podem ser de domínio apenas de alguns 'especialistas', e sim apropriados pelo maior número possível de profissionais da educação", dentre eles, principalmente o professor. Para tanto, "é essencial” a "formulação de políticas para a continuada formação" dos professores pelos "sistemas de ensino". Além de tal formação, a inclusão de alunos PAEE no Ensino Superior "requer medidas que facilitem e auxiliem a concretização desse processo", como "a produção e adequação de recursos pedagógicos, a assessoria psicopedagógica, a adaptação do currículo e a reflexão de todos os envolvidos no processo educativo", bem como a "criação de comissões ou núcleos na própria instituição responsáveis pelo desenvolvimento de ações que propiciem a inclusão" (PACHECO E COSTAS, 2006, p. 157).

Em suas respostas, a Professora "P" apresenta uma visão favorável ao processo de inclusão educacional dos alunos PAEE. Segunda ela,

A inclusão é um direito dos alunos com deficiência e a escola precisa, cada vez mais, buscar formas de oferecer condições para que essas pessoas se desenvolvam plenamente conforme suas capacidades individuais. Penso que a inclusão não será verdadeiramente efetivada por meio da Lei, mas que a Lei garante a inclusão na Instituição e cabe aos profissionais da educação garantir a inclusão por meio da aprendizagem dos conteúdos e das atividades desenvolvidas no espaço escolar (Professora "P", 2016). 
Assim como a Professora "P", Mendes e Bastos (2016, p. 197) afirmam que, "apesar de respaldo legal, existem muitos desafios a serem enfrentados para a concretização da inclusão nas IES”, pois a legislação é “necessária para nortear o trabalho pedagógico, mas não podemos considerá-la suficiente para garantir aos estudantes a graduação". Para Moreira (2005, p. 43), os aparatos legais, "sem dúvida, são importantes e necessários para a inclusão no Ensino Superior brasileiro, muito embora, por si só não garantam a efetivação de políticas e programas inclusivos”. A existência de uma "educação que prime pela inclusão" requer "investimentos em materiais pedagógicos, em qualificação de professores, em infraestrutura adequada para garantir acesso e permanência e estar atento a qualquer forma discriminatória". Para Miranda (2008, p. 41), a “inclusão só se efetivará se ocorrerem transformações estruturais no sistema educacional”.

Apesar do trabalho realizado pela Professora "P" ser pautado em sua formação inicial e em Psicopedagogia, e nas próprias iniciativas, sem o respaldo de uma formação continuada, ela considera que a aprendizagem da aluna surda presente em sua sala de aula é satisfatória "pelos resultados obtidos". Essa aluna, que faz leitura labial e uso da Língua Brasileira de Sinais (doravante LIBRAS) para se comunicar, "consegue acompanhar a turma nas atividades da sala de aula, nas avaliações e produções escritas e nas apresentações de trabalhos orais". Ainda segundo essa docente, "não fizemos adaptações" (se referindo a adaptações físicas e curriculares), pois a aluna "tem à sua disposição um intérprete que a auxilia nas atividades teóricas e práticas e na medida do possível nós professores tentamos estabelecer o diálogo com ela".

Segundo Mendes e Bastos (2016, p. 198), para a efetivação de uma prática educacional inclusiva que propicie a existência de uma educação inclusiva, os professores das IES precisam "considerar as diferenças linguísticas e as necessidades específicas de aprendizagem" dos alunos surdos. É necessário "reorganizar as estratégias de ensino" para que estes alunos tenham acesso ao conhecimento. As "dificuldades de leitura e escrita" enfrentadas por eles "acabam desviando sua energia e atenção na construção de conhecimentos", por isso, é preciso "direcionar a aprendizagem àquilo que tenha aplicabilidade no dia a dia", a fim de lhes "proporcionar um nível razoável de compreensão dos acontecimentos e o desenvolvimento de habilidades sociais e profissionais" (VIROLE, 2005 apud BISOL; VALENTINI; 
A inclusão de alunos público-alvo da educação especial na educação superior: um estudo de caso sobre o trabalho docente com uma

SIMIONI; ZANCHIN, 2010, p. 151) ${ }^{17}$. Além disso, segundo Fernandes (2008, p. 03), os professores precisam reconhecer a "situação bilíngue" em que os alunos surdos estão inseridos, que prevê a LIBRAS como primeira Língua para se comunicar oralmente e a Língua Portuguesa como segunda Língua, para a escrita. A garantia dessa "situação" é essencial para que não haja somente uma "pseudo-inclusão" destes alunos.

Nessa reorganização do ensino, é importante que o professor reconheça, portanto, o "direito" que os alunos surdos têm de "comunicar-se por língua de sinais", garantido pelo Decreto $n^{\circ} 5.626 / 05$, que regulamenta a Lei $n^{\circ} 10.436 / 2002$, em seu Capítulo IV, artigo $14, \S 1^{\circ}$, inciso I, alínea c, o “ensino da Língua Portuguesa como segunda língua para pessoas surdas” (BRASIL, 2005). Mendes e Bastos (2016, p. 199) ainda alertam sobre o papel do intérprete, já que em algumas Instituições "transfere-se a responsabilidade de aprendizagem" do aluno surdo para este profissional. Entretanto, "a orientação da Instrução 003/2012, que estabelece as normas para a atuação do tradutor e intérprete de Libras/Língua Portuguesa-TILS", dispõe que "esse profissional tem a função de oferecer suporte pedagógico à escolarização de alunos surdos" pela sua "mediação linguística" com os "demais membros da comunidade escolar"; porém, a "responsabilidade pela aprendizagem do estudante surdo é dos professores das disciplinas".

Assim, mesmo a aluna surda apresentando bons resultados nos estudos e tendo o auxílio do intérprete, cabe à Professora "P", em conjunto com os demais professores dessa aluna e com a IES, refletir sobre possíveis "adaptações curriculares", sobre a reorganização das estratégias de ensino, partindo sempre do reconhecimento da "situação bilíngue" em que esta aluna está imersa, a fim de garantir-lhe o acesso ao conhecimento e atenuar as dificuldades que possam existir durante o processo de aprendizagem.

\section{c) A IES e o processo de inclusão (questões discutidas: 5, 7, 12 e 13).}

A respeito dos "recursos necessários" para a inclusão de alunos PAEE na Educação Superior, como explicitado na introdução deste artigo, foi possível identificar, nas respostas dadas pela professora, que a gestão da IES em que atua, "tomou providência para a contratação de um intérprete para a aluna" tanto no processo seletivo quanto após sua aprovação e ingresso nessa Instituição para a realização do curso de Pedagogia, o que se constitui, segundo Mendes e Bastos (2016, p. 192-193), em “ações

17 VIROLE, B. Adolescence et surdité. 2005. 
importantes" para viabilizar o acesso de alunos PAEE na Educação Superior. Para Miranda (2006, p. 6), não podemos esquecer que todo aluno surdo "deve ter um intérprete em LIBRAS" na Instituição em que estuda.

Segundo a professora "P", a IES em que atua também oferece em sua matriz curricular três disciplinas que tratam especificamente da Educação Especial: "Temos as disciplinas 'Educação Especial e Inclusão', 'Educação e Diversidade', que trabalha a relevância do professor considerar a diversidade no processo educativo, e 'LIBRAS"'. No que se refere a esta última disciplina, tal instituição tem cumprido o que dispõe o Decreto $\mathrm{n}^{\circ} 5.626 / 05$, artigo $3^{\circ}$, que prevê que a "Libras deve ser inserida como disciplina curricular obrigatória nos cursos de formação de professores para o exercício do magistério, em nível médio e superior”. Dentre estes cursos, o $\$ 1^{\circ}$ deste artigo faz menção ao curso de Pedagogia.

Entretanto, segundo a Professora "P", nessa IES a aluna surda não recebe o AEE:

A aluna, não tem esse atendimento, e penso que também não necessita. Ela tem muita independência intelectual e física. É uma pessoa que, mesmo com a deficiência, tem agilidade e inteligência na solução de seus problemas práticos e acadêmicos. Ela está cursando o sétimo semestre, último ano do curso de pedagogia (Professora "P", 2016).

Mesmo sendo reconhecido pelo Decreto $\mathrm{n}^{\mathrm{o}} 7.611 / 11$, em seu artigo $5^{\circ}$, a “estruturação de núcleos de acessibilidade nas instituições federais”, o oferecimento do AEE no Ensino Superior, como afirmam Anache, Rovetto e Oliveira (2014, p. 303), é recente, ainda sendo oferecido em poucas IES. Contudo, há também por parte dessas instituições uma constante busca por oferecer outros recursos que contribuam para derrubar as "barreiras físicas, metodológicas e programáticas" ainda existentes, a fim de viabilizar o acesso, a permanência e a conclusão de cursos superiores por alunos PAEE, e assim efetivar o processo de inclusão desses alunos na Educação Superior. Tal afirmação também é trazida pela Professora "P" em sua fala: "Acredito que as instituições educativas estão melhorando cada vez mais o atendimento de alunos com deficiência”. Tal instituição "é lugar de todos e é necessário oferecer condições de aprendizagem e sucesso para todos os seus alunos" (Professora "P”, 2016).

\section{d) A relação docente - instituição - família (questão discutida: 10).}

Quando questionada sobre seu contato com a família da aluna surda e como os familiares participam da escolarização da filha, a Professora "P" relatou: 
Pelo que sei e percebo, essa aluna teve grande apoio da família, principalmente da mãe; os pais são ouvintes. A mãe tem contato frequente com a coordenação do curso de pedagogia, que a filha frequenta. Na família, são duas meninas com essa deficiência, e as duas conseguiram chegar ao Ensino Superior. A irmã mais velha, também foi nossa aluna e concluiu o curso de Pedagogia em 2013. Percebemos que a mãe tem muito conhecimento sobre a deficiência delas e busca ajudar e solicitar de quem é de responsabilidade a ajuda necessária para as filhas se desenvolverem bem. A própria mãe estudou e aprendeu LIBRAS e ensinou essa língua às duas filhas. Esse apoio da família é muito importante e faz diferença no desenvolvimento de alunos com deficiência; quando os pais não aceitam a deficiência do filho tudo se torna mais difícil, inclusive para nós professores (Professora "P”, 2016).

Em sua fala, a professora "P" destaca o relacionamento próximo que a mãe da aluna surda mantém com a coordenação do curso de Pedagogia. Segundo Rocha e Miranda (2009, p. 205), essa "sensibilização de professores, coordenadores de curso, e da família tem sido exclusivamente" uma das causas da "permanência" dos alunos PAEE nas IES. Para Reis (2010, p. 16-17), a "participação da família é uma necessidade contemporânea, almejada por todos que fazem parte do contexto escolar. Lidar com famílias hoje, é lidar com a diversidade”. A “família e a escola são pontos de apoio e sustentação ao ser humano", assim, "quanto melhor for a parceria entre ambas, mais positivos e significativos serão os resultados na formação do sujeito". Essa importância da união entre a família e a Instituição Escolar também é destacada pela Professora "P" em sua fala.

\section{Considerações finais}

Após verificar como ocorreu historicamente no Brasil o acesso e a permanência dos alunos PAEE na Educação Superior e como está se configurando seu processo de inclusão nas IES, o objetivo desta pesquisa foi investigar como vem se desenvolvendo o trabalho de uma professora com uma aluna surda em uma sala de aula comum, no curso de Pedagogia de uma IES. Os resultados obtidos com a entrevista realizada com esta docente apontam que está sendo garantido a essa aluna o acesso e a permanência nesta Instituição, e, provavelmente, a conclusão de seus estudos, visto que ela está no sétimo semestre deste curso.

Como mostra a bibliografia consultada, tal situação pode ser considerada positiva, pois esta garantia, principalmente no que tange à permanência de alunos PAEE 
na Educação Superior, ainda hoje se mostra insuficiente em muitos casos. Assim, entende-se que o bom desempenho apresentado pela aluna surda em seus estudos está ligado a três questões: a) à estreita relação da família com a IES e ao apoio familiar recebido pela aluna, que contribuem tanto para a garantia de oferta dos recursos que são reconhecidamente direito seus, quanto para uma formação significativa; b) aos recursos efetivamente oferecidos pela IES, desde seu ingresso até o momento, quando se aproxima a conclusão dos seus estudos; e c) à iniciativa da professora entrevistada ao buscar, a partir de sua formação inicial e em Psicopedagogia, realizar um trabalho voltado a atender as dificuldades desta aluna para garantir-lhe sucesso no curso.

Porém, mesmo diante dessa situação favorável, ainda é possível identificar nas falas da professora a ausência em seu trabalho de uma "prática educativa inclusiva", o que impede, consequentemente, a constituição de uma educação inclusiva. Segundo a bibliografia consultada, a efetividade do processo de inclusão educacional requer o desenvolvimento dessa prática, uma vez que tal processo não implica apenas na "presença física" dos alunos, neste caso dos alunos PAEE, na sala de aula comum, mas um trabalho educativo que atenda todas as suas necessidades educacionais especiais, garantindo assim sua aprendizagem. Em relação ao aluno surdo, como alvitrado anteriormente, há a necessidade de uma reorganização nas estratégias de ensino a partir do reconhecimento da "situação bilíngue" em que estes alunos estão inseridos (FERNANDES, 2008, p. 03).

Como visto, a construção dessa "prática pedagógica inclusiva" requer não apenas a iniciativa e o reconhecimento do professor da importância da inclusão de alunos PAEE na Educação Superior, e das diferenças e necessidades de todos os seus alunos, como demonstrado pela docente entrevistada em suas falas, mas também o oferecimento pelos sistemas de ensino de uma "formação continuada" a esse profissional para que ele seja "apto a elaborar e implantar novas propostas e práticas de ensino para responder às características de todos os seus alunos" (PRIETO, 2006, p. $57)$.

AGRADECIMENTOS: FAPESP (Fundação de Amparo à Pesquisa do Estado de São Paulo), pela concessão da bolsa de estudos que permitiu a concretização deste trabalho.

\section{REFERÊNCIAS}


A inclusão de alunos público-alvo da educação especial na educação superior: um estudo de caso sobre o trabalho docente com uma aluna surda no curso de pedagogia

ALMEIDA, E. G.; SILVINO, F. F. Abordagem qualitativa e suas possibilidades de aplicação em pesquisas na Linguística Aplicada. Disponível em:<https://estagio320102.wikispaces.com/file/view/abordagem_qualitativa_em_dois_projetos_de_pesquisa _LA.pdf>. Acesso em: 23 maio 2016.

ALVES-MAZZOTTI, A. J. Usos e abusos dos Estudos de Caso. Cadernos de Pesquisa, v. 36, n. 129, p. 637-651, set./dez., 2006.

ANACHE, A. A.; ROVETTO, S. S. M.; OLIVEIRA, R. A. Desafios de implantação do atendimento educacional especializado no Ensino Superior. Revista Educação Especial, v. 27, n.49, p. 299-312, maio/ago., 2014.

BEJA, A. C.; REZENDE, F. Processos de construção da identidade docente no discurso de estudantes da licenciatura em Química. Revista Electrónica de Enseñanza de las Ciencias, v. 13, n. 2, p. 156-178, 2014.

BISOL, C. A.; VALENTINI, C. B.; SIMIONI, J. L.; ZANCHIN, J. Estudantes surdos no ensino superior: reflexões sobre a inclusão. Cadernos de Pesquisa, v. 40, n. 139, p.147-172, jan./abr., 2010.

BRASIL. Constituição da República Federativa do Brasil de 1988. Disponível em:< http://www.planalto.gov.br/ccivil_03/Constituicao/Constituicao.htm>. Acesso em: 12 abr. 2016.

BRASIL. Ministério da Educação. Aviso Circular no 277/MEC/GM de 08 de maio de 1996. Dirigido aos Reitores das IES, solicitando a execução adequada de uma política educacional dirigida aos portadores de necessidades especiais. Brasília, 1996.

BRASIL. Ministério da Educação. Decreto no 5.626 de 22 de dezembro de 2005. Regulamenta a Lei $\mathrm{n}^{\circ} 10.436$, de 24 de abril de 2002, que dispõe sobre a Língua Brasileira de Sinais - Libras, e o art. 18 da Lei n ${ }^{\circ}$ 10.098, de 19 de dezembro de 2000. Brasília, 2005.

BRASIL. Ministério da Educação. Decreto no 7.611 de 17 de novembro de 2011. Dispõe sobre a educação especial, o atendimento educacional especializado e dá outras providências, Brasília, 2011.

BRASIL. Política Nacional de Educação Especial na Perspectiva da Educação Inclusiva. MEC/SEESP, 2008. Disponível em:

<http://peei.mec.gov.br/arquivos/politica_nacional_educacao_especial.pdf >. Acesso em: 31 mar. 2016.

BRITO, A. E. C. A.; QUIRINO, D. L. C.; PORTO, L. C. M. Educação Especial e Inclusiva no Ensino Superior. Revista de Educação, v. 16, n. 20/21, p. 14-20, 2013.

CAMPOS, A. M. O Plano Nacional de Educação (2011-2020) e a Educação Especial na Perspectiva da Educação Inclusiva: propostas e desafios. Disponível em:<www.anpae.org.br/simposio2011/cdrom2011/PDFs/trabalhosCompletos/.../0074.p df>. Acesso em: 08 abr. 2016. 
CASTANHO, D. M.; FREITAS, S. N. Inclusão e prática docente no ensino superior. Revista Educação Especial, n.27, p. 93-99, 2006.

FERNANDES, S. Letramentos na educação bilíngue para surdos: caminhos para a prática pedagógica. Universidade Federal do Paraná (UFPR). Curitiba, p. 02-03, 2008.

FERRARI, M. A. L. D.; SEKKEL, M. C. Educação Inclusiva no Ensino Superior: um novo desafio. Revista Psicologia, Ciência e Profissão, v. 27, n. 4, p. 636-647, 2007.

MENDES, H. S. F.; BASTOS, C. C. B. C. Um estudo sobre a realidade da inclusão de pessoas com deficiência na educação superior no Paraná. Revista Educação Especial, v. 29, n. 54, p. 189-202, jan./abr., 2016.

MIRANDA. T. G. A inclusão de pessoas com deficiência na universidade. In: Anais... Seminário de Pesquisa em Educação Especial, Vitória: UFES, 2006.

MIRANDA, A. A. B. Educação Especial no Brasil: desenvolvimento histórico. Cadernos de História da Educação, n. 7, p. 29-44, jan./dez., 2008.

MOREIRA, L. C. Universidade e estudantes com necessidades educacionais especiais: das ações institucionais às práticas pedagógicas. São Paulo: USP, 2004. Tese (Doutorado em Educação). Faculdade de Educação da Universidade de São Paulo, 2004, p. 36.

PACHECO, R. V.; COSTAS, F. A. T. O processo de inclusão de acadêmicos com necessidades educacionais especiais na Universidade Federal de Santa Maria. Revista Educação Especial, n. 27, p. 151-167, 2006.

PERRENOUD, P. A prática reflexiva e o ofício do professor: profissionalização e razão pedagógica. In: Saber refletir sobre a própria prática: objetivo central da formação de professores. Tradução Cláudia Schilling. Porto Alegre: Artmed, 2002.

PRIETO, R. G. Atendimento escolar de alunos com necessidades educacionais especiais: um olhar sobre as políticas públicas de educação no Brasil. In: MANTOAN, M. T. E.; PRIETO, R.G.; ARANTES, V.A. (Orgs.). Inclusão Escolar: pontos e contrapontos. São Paulo: Summus, 2006.

REIS, L. P. C. A participação da família no contexto escolar. 2010. 62 f. Monografia (Graduação em Pedagogia), Departamento de Educação, Universidade do Estado da Bahia, Salvador, 2010.

ROCHA, T. B.; MIRANDA, T. G. Acesso e permanência do aluno com deficiência na instituição de ensino superior. Revista Educação Especial, v. 22, n. 34, p. 197-212, maio/ago., 2009.

SILVA, C. R.; GOBBI, B. C.; SIMÃO, A. A. O uso da análise de conteúdo como uma ferramenta para a pesquisa qualitativa: descrição e aplicação do método. Organizações Rurais \& Agroindustriais, Lavras, v. 7, n. 1, p. 70-81, 2005. 
A inclusão de alunos público-alvo da educação especial na educação superior: um estudo de caso sobre o trabalho docente com uma aluna surda no curso de pedagogia

SILVA, L. M. G. Educação especial e inclusão escolar sob a perspectiva legal.

Anais... Simpósio Estado Políticas, Universidade Federal de Uberlândia, Disponível em: <http://www.simposioestadopoliticas.ufu.br/imagens/anais/pdf/BP05.pdf >. Acesso em: 13 maio 2016.

VIEIRA, G. M. Educação Inclusiva no Brasil: do contexto histórico à contemporaneidade. Disponível

em:<https://www.posgraduacaoredentor.com.br/hide/path_img/conteudo_542346c1637 83.pdf.>. Acesso em: 13 maio 2016.

\section{Como referenciar este artigo:}

SBRANA, Roberta Aline.; CARNEIRO, Relma Urel Carbone. A inclusão de alunos público-alvo da educação especial na educação superior: um estudo de caso sobre o trabalho docente com uma aluna surda no curso de pedagogia. Temas em Educação e Saúde, Araraquara, v.14, n.1, p. 121-141, jan./jun., 2018. E-ISSN: 2526-3471. DOI: 10.26673/rtes.v14.n1.2018.11219.

Submetido em: 21/02/2018

Aprovado em: 06/05/2018 